\title{
Pulmonary hemodynamic profile in chronic obstructive pulmonary disease
}

\author{
This article was published in the following Dove Press journal: \\ International Journal of COPD \\ 14 July 2015 \\ Number of times this article has been viewed
}

\author{
Karina Portillo' \\ Yolanda Torralba ${ }^{1,2}$ \\ Isabel Blancol,2 \\ Felip Burgos 1,2 \\ Roberto Rodriguez-Roisin ${ }^{1,2}$ \\ Jose Rios ${ }^{3}$ \\ Josep Roca ${ }^{1,2}$ \\ Joan A Barberà ${ }^{1,2}$ \\ 'Department of Pulmonary \\ Medicine, Hospital Clínic-Institut \\ d'Investigacions Biomèdiques August \\ Pi iSunyer (IDIBAPS), University of \\ Barcelona, Barcelona, Spain; ${ }^{2}$ Centro \\ de Investigación Biomédica en \\ Red de Enfermedades Respiratorias \\ (CIBERES), Madrid, Spain; ${ }^{3}$ Biostatistics \\ and Data Management Core Facility, \\ Hospital Clínic-Institut d'Investigacions \\ Biomèdiques August Pi iSunyer \\ (IDIBAPS), Biostatistics Unit, School \\ of Medicine, Universitat Autònoma \\ de Barcelona, Barcelona, Spain
}

Correspondence: Joan A Barberà Department of Pulmonary Medicine, Hospital Clínic, Villarroel I70, 08036 Barcelona, Spain

Tel +34932 275747

Fax +34932 255455

Email jbarbera@clinic.ub.es
Introduction: Few data are available in regards to the prevalence of pulmonary hypertension $(\mathrm{PH})$ in the broad spectrum of COPD. This study was aimed at assessing the prevalence of $\mathrm{PH}$ in a cohort of COPD patients across the severity of airflow limitation, and reporting the hemodynamic characteristics at rest and during exercise.

Methods: We performed a retrospective analysis on COPD patients who underwent right-heart catheterization in our center with measurements obtained at rest $(n=139)$ and during exercise $(\mathrm{n}=85)$. $\mathrm{PH}$ was defined as mean pulmonary artery pressure (mPAP) $\geq 25 \mathrm{mmHg}$ and pulmonary capillary wedge pressure $<15 \mathrm{mmHg}$. Exercise-induced PH (EIPH) was defined by a ratio of $\Delta \mathrm{mPAP} / \Delta$ cardiac output $>3$.

Results: $\mathrm{PH}$ was present in 25 patients (18\%). According to the Global Initiative for Chronic Obstructive Lung Disease (GOLD) classification, PH prevalence in GOLD 2 was 7\% (3 patients); $25 \%$ (14 patients) in GOLD 3; and 22\% (8 patients) in GOLD 4. Severe PH ( $\mathrm{mPAP} \geq 35 \mathrm{mmHg}$ ) was identified in four patients $(2.8 \%)$. Arterial partial oxygen pressure was the outcome most strongly associated with PH $(r=-0.29, P<0.001)$. EIPH was observed in 60 patients $(71 \%)$ and had a similar prevalence in both GOLD 2 and 3, and was present in all GOLD 4 patients. Patients with $\mathrm{PH}$ had lower cardiac index during exercise than patients without $\mathrm{PH}(5.0 \pm 1.2$ versus $6.7 \pm 1.4 \mathrm{~L} / \mathrm{min} / \mathrm{m}^{2}$, respectively; $P=0.001$ ).

Conclusion: $\mathrm{PH}$ has a similar prevalence in COPD patients with severe and very-severe airflow limitation, being associated with the presence of arterial hypoxemia. In contrast, EIPH is highly prevalent, even in moderate COPD, and might contribute to limiting exercise tolerance.

Keywords: pulmonary hypertension, right heart catheterization, cardiac index, GOLD

\section{Introduction}

Pulmonary hypertension $(\mathrm{PH})$ is a relevant complication in the natural history of patients with chronic obstructive pulmonary disease (COPD), since its presence is associated with shorter survival, increased risk of exacerbations, and greater use of health care resources. ${ }^{1}$ The actual prevalence of $\mathrm{PH}$ in COPD remains unsettled and varies widely according to the targeted population, the definition applied, and the diagnostic approach used to identify $\mathrm{PH}^{2}{ }^{2}$ Right-heart catheterization is the gold standard to diagnose $\mathrm{PH} .{ }^{3}$ In COPD, most hemodynamic studies have been performed in patients with advanced disease in whom $\mathrm{PH}$ is expected to occur more frequently, with a prevalence of $\mathrm{PH}$ ranging from 23\%-91\%. ${ }^{4-12}$ Information on the prevalence of $\mathrm{PH}$ in patients with milder disease is scarce. Based on the former Global Initiative for Chronic Obstructive Lung Disease (GOLD) spirometric classification, ${ }^{13}$ Hilde et $\mathrm{al}^{14}$ reported a prevalence of 5\%,27\%, and 53\% in patients with GOLD stages 2, 3, and 4 , respectively.

Patients with COPD may develop PH during exercise, a condition associated with an increased risk for subsequently developing $\mathrm{PH}$ at rest. ${ }^{12}$ Current understanding of 
the hemodynamic response of the pulmonary circulation to exercise in patients with COPD and its impact over exercise intolerance is limited. Studies have shown a cardiovascular limitation to exercise in patients with severe $\mathrm{PH}$ which seems to be distinct from the ventilatory exhaustion usually observed in COPD. ${ }^{15,16}$

In order to expand our understanding of the hemodynamic profile of $\mathrm{PH}$ across the spirometric degrees of COPD, we analyzed data from 139 COPD patients assessed by right-heart catheterization at rest. A subset of these patients $(n=85)$ had hemodynamic measurements during exercise. The main objective of the present study was to assess the prevalence of $\mathrm{PH}$ in this cohort of patients according to the GOLD spirometric grades. Secondary aims were to describe the hemodynamic characteristics at rest and during exercise, and to analyze the potential relationships between pulmonary hemodynamics and lung function tests.

\section{Methods}

This was a retrospective study, which included data from seven previously reported studies. ${ }^{17-23}$ All studies were approved by our institutional ethics committee and the procedures were performed after obtaining written informed consent. All involved patients were clinically stable (ie, at least 3 months from the last COPD exacerbation), without cardiac failure or other coexisting chronic respiratory disease, and received regular treatment for COPD, including long-term oxygen if it was deemed necessary. No patient was treated with PH targeted therapy, namely prostanoids, endothelin-receptor antagonists, or phosphodiesterase-5 inhibitors. All were current $(n=53)$ or former $(n=86)$ smokers ( $\geq 10$ pack-year). Patients were classified according to the GOLD spirometric grade system. ${ }^{24}$

PH was defined by a mean pulmonary artery pressure (mPAP) $\geq 25 \mathrm{mmHg}$ and a pulmonary capillary wedge pressure $(\mathrm{PCWP})<15 \mathrm{mmHg}$. ${ }^{2}$ Severe $\mathrm{PH}$ was considered when mPAP was $\geq 35 \mathrm{mmHg}$ or $\geq 25 \mathrm{mmHg}$ along with a cardiac index $(\mathrm{CI})<2.0 \mathrm{~L} / \mathrm{min} / \mathrm{m}^{2}$, according to the most updated clinical classification of $\mathrm{PH}$ in chronic lung diseases. ${ }^{3}$ An abnormal increase of mPAP during exercise was considered when the change in mPAP ([ $\Delta \mathrm{mPAP}]$ in $\mathrm{mmHg})$ was $>3$ times greater than the change in cardiac output $([\mathrm{CO}]$ in $\mathrm{L} / \mathrm{min})(\Delta \mathrm{CO}) .{ }^{14,25}$ As age may influence exercise mPAP, we also analyzed the mPAP values during exercise according to those reported by Kovacs et $\mathrm{al}^{26}$ who established the upper limit of normal as $30 \mathrm{mmHg}$ for subjects $<50$ years and as $46 \mathrm{mmHg}$ for subjects $\geq 50$ years.

\section{Measurements}

\section{Lung function}

Forced spirometry, static lung volumes, and single-breath carbon monoxide diffusing capacity (DLco) were measured according to the American Thoracic Society/European Respiratory Society recommendations, ${ }^{27}$ using our own predicted equations. ${ }^{28-29}$ Arterial blood gas samples were drawn for measuring partial pressure of arterial oxygen $\left(\mathrm{PaO}_{2}\right)$, partial pressure of arterial carbon dioxide $\left(\mathrm{PaCO}_{2}\right)$, and $\mathrm{pH}$ at rest and during exercise.

\section{Right-heart catheterization}

A triple-lumen Swan-Ganz catheter (Edwards Laboratories, Santa Ana, CA, USA) was placed into the pulmonary artery under pressure wave monitoring (M1166A; Hewlett-Packard, Boeblingen, Germany). Transducers were zeroed at the level of right atrium. Right atrial pressure (RAP), pulmonary artery pressure (PAP), and PCWP were measured at the end of expiration. $\mathrm{CO}$ was measured by thermodilution and expressed as the mean of three measurements. CI, pulmonary vascular resistance (PVR), and total pulmonary resistance were calculated using standard formulae. ${ }^{30}$

\section{Exercise measurements}

Prior to catheterization, the highest workload that patients could tolerate was determined by an incremental exercise test on a cycle ergometer in 85 subjects. The workload was increased using a ramp of 5 Watts every minute until the maximal load limited by symptoms was achieved. Hemodynamic and gas exchange measurements were performed in the semirecumbent position at a workload equivalent to $60 \%$ of the maximal workload tolerated in the previous incremental test.

\section{Statistical analysis}

Data are expressed as mean \pm standard deviation unless otherwise stated. One-way analysis of variance with Bonferroni correction was used to compare more than two groups. Relationships between variables were assessed using Pearson's or Spearman's correlation coefficients depending on data distribution. Changes in hemodynamic data from rest to exercise were compared using paired $t$-tests. The MannWhitney $U$-test was used to assess CI during exercise in patients with and without $\mathrm{PH}$. Estimations of risk for $\mathrm{PH}$ were made using odds ratios and their 95\% confidence intervals from univariate logistic regression models for $\mathrm{PaO}_{2}, \mathrm{DLco}$, $\mathrm{PaCO}_{2}$, inspiratory capacity, or forced expiratory volume in 1 second $\left(\mathrm{FEV}_{1}\right)$. In order to assess a multivariate model, we 
used a forward stepwise procedure with a criterion of 0.05 to select variables for the final model. All data were analyzed with SPSS version 18 and $P$-values $<0.05$ were considerate as statistically significant.

\section{Results}

The means ( \pm standard deviation) of demographic and lung function measurements for all participants are given in Table 1 as a function of the current GOLD spirometric classification. ${ }^{24}$ One hundred and thirty-nine patients (134 men, 5 women) were included. Mean age was $63 \pm 8$ years. The mean of post-bronchodilator $\mathrm{FEV}_{1}$ was $41 \% \pm 16 \%$ of predicted; $\mathrm{PaO}_{2}$ was $69 \pm 12 \mathrm{mmHg} ; \mathrm{PaCO}_{2}$ was $40 \pm 6$; and alveolararterial oxygen partial pressure difference $\left(\mathrm{AaPO}_{2}\right)$ was $32 \pm 10 \mathrm{mmHg}$. Thirty-seven patients were under long-term oxygen therapy.

\section{Hemodynamic characteristics at rest}

Table 2 shows the hemodynamic measurements at rest. The mean mPAP of the whole cohort was $20 \pm 8 \mathrm{mmHg}$. PH was present in 25 patients (18\% of cases of the whole cohort). Most of them had severe or very-severe airflow limitation, although PH prevalence was similar in GOLD 3 and 4.

Mean PVR was normal in GOLD 2 and 3, although with a wide dispersion, and elevated in GOLD 4. RAP, PCWP, and
CI were on average within normal range in all GOLD grades. The CI correlated with $\mathrm{FEV}_{1}(r=0.38, P<0.001)$. Severe $\mathrm{PH}$ was noticed in four patients $(2.8 \%$ of the whole cohort). All of them were male. Their lung function and hemodynamic characteristics are listed in Table 3.

\section{Hemodynamic characteristics during exercise and changes in blood gases}

Both MPAP and PCWP increased significantly during exercise in all GOLD grades (Figure 1; Table 4). An abnormal increase of mPAP during exercise, defined by a $\triangle \mathrm{mPAP} / \triangle \mathrm{CO}$ ratio $>3$, was observed in 60 patients $(71 \%)$ : 28 patients $(70 \%)$ were in GOLD 2, 26 (67\%) in GOLD 3, and the remaining six patients in GOLD 4. During exercise, patients with $\mathrm{PH}$, compared with those without $\mathrm{PH}$, had lower CI $\left(5.0 \pm 1.2\right.$ and $6.7 \pm 1.4 \mathrm{~L} / \mathrm{min} / \mathrm{m}^{2}$, respectively; $\left.P=0.001\right)$ (Figure 2). Patients with associated $\mathrm{PH}$ had, as compared with patients without $\mathrm{PH}$, lower $\mathrm{PaO}_{2}$ and higher $\mathrm{PaCO}_{2}$ both at rest and during exercise (Table 5).

\section{Variables associated with $\mathrm{PH}$}

In the univariate analysis, the following outcomes were associated with the presence of $\mathrm{PH}$ at rest: $\mathrm{PaO}_{2}$; DLco (\% predicted); $\mathrm{PaCO}_{2}$; inspiratory capacity (\% predicted); and $\mathrm{FEV}_{1}(\%$ predicted $)$. In the stepwise multiple regression

Table I Anthropometric and functional characteristics of 139 patients grouped according to GOLD spirometric grades

\begin{tabular}{|c|c|c|c|c|c|}
\hline & \multirow[t]{2}{*}{ All } & \multicolumn{3}{|c|}{ GOLD grade } & \multirow{2}{*}{$\begin{array}{l}\text { ANOVA } \\
\text { P-value }\end{array}$} \\
\hline & & 2 & 3 & 4 & \\
\hline $\mathrm{N}$ & 139 & 46 & 56 & 37 & \\
\hline Sex, M/F & $134 / 5$ & $46 / 0$ & $53 / 3$ & $35 / 2$ & \\
\hline Age (yr) & $63 \pm 8$ & $63 \pm 8$ & $63 \pm 7$ & $60 \pm 7$ & NS \\
\hline $\mathrm{BMI}\left(\mathrm{m} / \mathrm{kg}^{2}\right)$ & $25 \pm 4$ & $24 \pm 4$ & $26 \pm 3$ & $24 \pm 4$ & NS \\
\hline FVC (\% pred) & $72 \pm 18$ & $82 \pm 14$ & $7 I \pm I 7 *$ & $60 \pm 17^{*, \neq}$ & $<0.001$ \\
\hline $\mathrm{FEV}_{\mathrm{I}}(\mathrm{L})$ & $1.3 \pm 0.6$ & $1.9 \pm 0.5$ & $1.2 \pm 0.2^{*}$ & $0.7 \pm 0.2^{*, \neq}$ & $<0.001$ \\
\hline FEV (\% pred) & $4 I \pm 16$ & $59 \pm 7$ & $39 \pm 6 *$ & $20 \pm 4 *, \neq$ & $<0.001$ \\
\hline FEV,/FVC (\%) & $40 \pm 15$ & $52 \pm 8$ & $4 I \pm 14^{*}$ & $25 \pm 8^{*}, \neq$ & $<0.001$ \\
\hline TLC (\% pred) & || $6 \pm 2 \mid$ & $113 \pm 17$ & $112 \pm 22$ & $124 \pm 22^{\neq}$ & 0.004 \\
\hline RV (\% pred) & $200 \pm 75$ & $156 \pm 44$ & $191 \pm 69 *$ & $266 \pm 68^{* * \neq}$ & $<0.001$ \\
\hline IC (\% pred) & $62 \pm 18$ & $76 \pm 16$ & $63 \pm 16^{*}$ & $47 \pm 12^{*, \neq}$ & $<0.001$ \\
\hline RV/TLC (\%) & $6 I \pm I I$ & $52 \pm 8$ & $59 \pm 9 *$ & $7 I \pm 8^{*}, \neq$ & $<0.001$ \\
\hline IC/TLC ratio & $0.26 \pm 0.07$ & $0.32 \pm 0.06$ & $0.27 \pm 0.07^{*}$ & $0.18 \pm 0.05^{*, \neq}$ & $<0.001$ \\
\hline DLco (\% pred) & $57 \pm 25$ & $72 \pm 23$ & $59 \pm 21 *$ & $36 \pm 15^{*, \neq}$ & $<0.001$ \\
\hline $\mathrm{PaO}_{2}(\mathrm{mmHg})$ & $69 \pm 12$ & $77 \pm 10$ & $68 \pm 11 *$ & $62 \pm 11 *, \neq$ & $<0.001$ \\
\hline $\mathrm{PaCO}_{2}(\mathrm{mmHg})$ & $40 \pm 6$ & $37 \pm 4$ & $4 I \pm 6 *$ & $45 \pm 7^{*, \neq}$ & $<0.001$ \\
\hline $\mathrm{AaPO}_{2}(\mathrm{mmHg})$ & $32 \pm 10$ & $30 \pm 11$ & $32 \pm 9$ & $34 \pm 10$ & NS \\
\hline
\end{tabular}

Notes: Data are presented as means \pm standard deviation. Significant differences within each variable are indicated as: ${ }^{*}$ different from GOLD grade $2 ;{ }^{\ddagger}$ different from GOLD grade 3.

Abbreviations: $\mathrm{AaPO}_{2}$, alveolar-arterial oxygen partial pressure difference; ANOVA, analysis of variance; BMI, body mass index; DLco, diffusing capacity for carbon dioxide; $\mathrm{FEV}_{1}$, post-bronchodilator forced expiratory volume in I second; FEV/FVC, post-bronchodilator forced expiratory volume in I second/post-bronchodilator forced vital capacity; FVC, post-bronchodilator forced vital capacity; GOLD, Global Initiative for Chronic Obstructive Pulmonary Disease; IC, inspiratory capacity; IC/TLC, inspiratory capacity/total lung capacity ratio; M/F, male/female; $\mathrm{NS}$, not significant; $\mathrm{PaCO}_{2}$, partial pressure of arterial carbon dioxide; $\mathrm{PaO}$, partial pressure of arterial oxygen; pred, predicted; RV, residual volume; RV/TLC, residual volume/total lung capacity ratio; TLC, total lung capacity. 
Table 2 Pulmonary hemodynamics at rest of 139 patients grouped according to the GOLD spirometric grades

\begin{tabular}{|c|c|c|c|c|c|}
\hline & \multirow[t]{2}{*}{ All } & \multicolumn{3}{|c|}{ GOLD grade } & \multirow{2}{*}{$\begin{array}{l}\text { ANOVA } \\
\text { P-value }\end{array}$} \\
\hline & & 2 & 3 & 4 & \\
\hline $\mathrm{N}$ & 139 & 46 & 56 & 37 & \\
\hline $\mathrm{mPAP}(\mathrm{mmHg})$ & $20 \pm 8$ & $18 \pm 6$ & $21 \pm 9$ & $21 \pm 6$ & NS \\
\hline PCWP (mmHg) & $6 \pm 4$ & $7 \pm 4$ & $6 \pm 4$ & $5 \pm 3$ & NS \\
\hline $\mathrm{RAP}(\mathrm{mmHg})$ & $2.9 \pm 3.2$ & $3.4 \pm 3.5$ & $2.1 \pm 3.2$ & $2.7 \pm 2.7$ & NS \\
\hline $\mathrm{CO}\left(\mathrm{L} / \mathrm{min} / \mathrm{m}^{2}\right)$ & $5.6 \pm I .4$ & $6.3 \pm 1.5$ & $5.5 \pm 1.3^{*}$ & $4.7 \pm 0.8^{*, \neq}$ & $<0.001$ \\
\hline $\mathrm{Cl}\left(\mathrm{L} / \mathrm{min} / \mathrm{m}^{2}\right)$ & $3.2 \pm 0.8$ & $3.6 \pm 0.8$ & $3.1 \pm 0.7^{*}$ & $2.8 \pm 0.6 *, \neq$ & $<0.001$ \\
\hline TPR (dyn.s.cm $\left.{ }^{-5}\right)$ & $306 \pm 158$ & $244 \pm 105$ & $322 \pm 197 *$ & $355 \pm|9|^{*, \neq}$ & 0.004 \\
\hline PVR (dyn $\left.\cdot \mathrm{s} \cdot \mathrm{cm}^{-5}\right)$ & $218 \pm 143$ & $160 \pm 88$ & $233 \pm 185^{*}$ & $264 \pm 97^{*, \neq}$ & 0.003 \\
\hline TPG & $14 \pm 7$ & $12 \pm 5$ & $15 \pm 8$ & $16 \pm 5^{*, \neq}$ & 0.02 \\
\hline Patients with $\mathrm{PH}, \mathrm{n}(\%)$ & $25(18)$ & $3(7)$ & $14(25)$ & $8(22)$ & \\
\hline
\end{tabular}

Notes: Data are presented as mean \pm standard deviation. Significant differences within each variable are indicated as: * different from GOLD grade $2 ;{ }^{\ddagger}$ different from GOLD grade 3.

Abbreviations: ANOVA, analysis of variance; Cl, cardiac index; CO, cardiac output; GOLD, Global Initiative for Chronic Obstructive Pulmonary Disease; mPAP, mean pulmonary artery pressure; NS, not significant; PCWP, pulmonary capillary wedge pressure; PH, pulmonary hypertension; PVR, pulmonary vascular resistance; RAP, right atrial pressure; TPG, transpulmonary pressure gradient; TPR, total pulmonary resistance.

model, $\mathrm{PaO}_{2}$ was the only covariate associated with the presence of PH (Table 6).

\section{Discussion}

The current study, which includes pulmonary hemodynamic measurements at rest and during exercise in a stable population of COPD across the whole spirometric spectrum of severity, identified several findings. First, the overall prevalence of $\mathrm{PH}$ in our cohort was relatively low (18\%). Second, patients in GOLD 3 and 4 had similar a prevalence of PH. Third, a significant increase of both MPAP and PCWP during exercise was noticed in all patients with a high proportion of an "exercise hypertensive response" in the entire cohort. And fourth, CI during exercise was affected by the presence of $\mathrm{PH}$.

Data about the prevalence of PH in COPD, particularly in patients with moderate-to-severe COPD, is limited. The prevalence found in our study was lower than in a recent study by Hilde et $\mathrm{al}^{14}$ who reported a prevalence of $\mathrm{PH}$ of $27 \%$ in stable patients in GOLD 2-4. Interestingly, the prevalence of $\mathrm{PH}$ observed in the present study in patients with GOLD 2 and 3 was similar to that reported by Hilde et al. ${ }^{14}$
In contrast, the prevalence of $\mathrm{PH}$ in patients with GOLD 4 was lower in our study (22\%) than in Hilde's study (53\%). This discrepancy may be due to the fact that the current GOLD spirometric classification, which we used, does not consider arterial blood gas measurements for the definition of GOLD $4 .{ }^{24}$ Accordingly, in patients with severe-to-verysevere COPD, the degree of airflow limitation is not related to the presence of $\mathrm{PH}$. What makes a difference regarding $\mathrm{PH}$ in those patients is the presence of concomitant abnormal pulmonary gas exchange. In fact, if we classify patients in our series according to the previous GOLD classification, the prevalence of $\mathrm{PH}$ in GOLD 4 stage is $33 \%$, in line with that reported by Hilde et al. ${ }^{14}$ That said, we cannot overlook that the current A-B-C-D GOLD classification, based on a multidimensional assessment of airflow limitation, symptoms, and risk of exacerbations, ${ }^{24}$ might more accurately identify differences in $\mathrm{PH}$ prevalence between categories. Nevertheless, the retrospective nature of our study precludes such a combined assessment.

As previously reported, the degree of $\mathrm{PH}$ in this cohort was of mild-to-moderate magnitude with a well preserved $\mathrm{CO}$, and mPAP correlated with airflow obstruction

Table 3 Subject characteristics in four COPD patients with severe pulmonary hypertension

\begin{tabular}{|c|c|c|c|c|c|c|c|c|}
\hline $\begin{array}{l}\text { Age } \\
\text { (years) }\end{array}$ & $\begin{array}{l}\text { FEV } \\
\text { (\% pred) }\end{array}$ & $\begin{array}{l}\text { DLco } \\
\text { (\% pred) }\end{array}$ & $\begin{array}{l}\mathrm{PaO}_{2} \\
(\mathrm{mmHg})\end{array}$ & $\begin{array}{l}\mathrm{PaCO}_{2} \\
(\mathrm{mmHg})\end{array}$ & $\begin{array}{l}\text { mPAP } \\
(\mathbf{m m H g})\end{array}$ & $\begin{array}{l}\text { PCWP } \\
(\mathrm{mmHg})\end{array}$ & $\begin{array}{l}\text { PVR } \\
\left(\text { dyn } \cdot \mathbf{s} \cdot \mathrm{cm}^{-5} \text { ) }\right.\end{array}$ & $\begin{array}{l}\mathrm{Cl} \\
\left(\mathrm{L} / \mathrm{min} / \mathrm{m}^{2}\right)\end{array}$ \\
\hline 58 & 35 & 34 & 44 & 46 & 35 & 4 & 594 & 2.75 \\
\hline 65 & 51 & 24 & 50 & 35 & 43 & 6 & 566 & 2.69 \\
\hline 58 & 46 & 22 & 50 & 38 & 38 & 2 & $\mathrm{I}, 080$ & 1.79 \\
\hline 61 & 39 & 21 & 46 & 44 & 61 & 11 & 941 & 2.38 \\
\hline
\end{tabular}

Abbreviations: COPD, chronic obstructive pulmonary disease; $\mathrm{Cl}$, cardiac index; DLco, diffusing capacity for carbon dioxide; FEV ${ }_{1}$, post-bronchodilator forced expiratory volume in I second; mPAP, mean pulmonary artery pressure; NS, not significant; $\mathrm{PaO}_{2}$, partial pressure of arterial oxygen; $\mathrm{PaCO}_{2}$, partial pressure of arterial carbon dioxide; PCWP, pulmonary capillary wedge pressure; pred, predicted; PVR, pulmonary vascular resistance. 


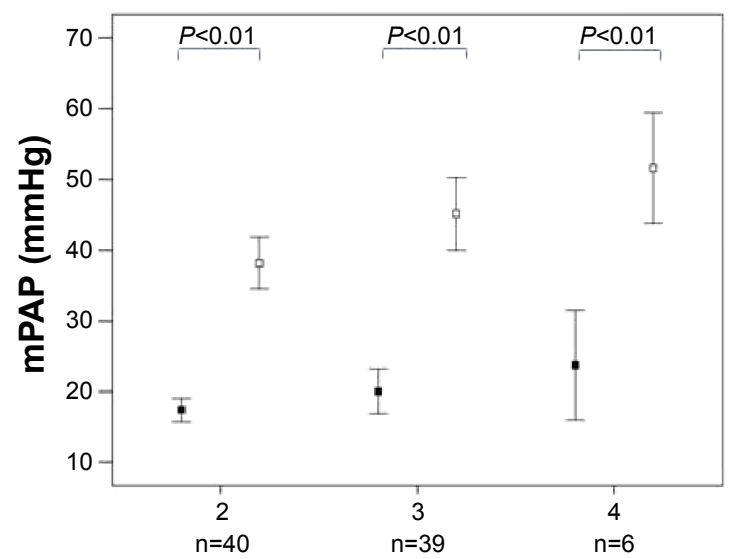

GOLD spirometric grades

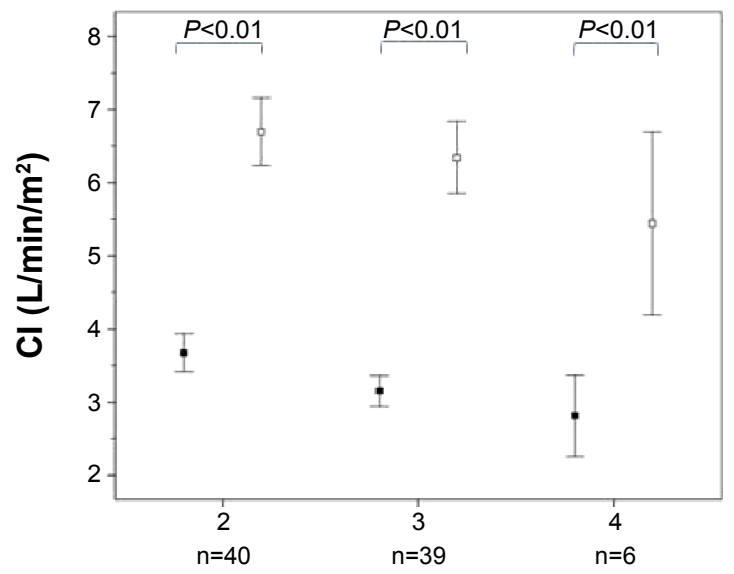

GOLD spirometric grades

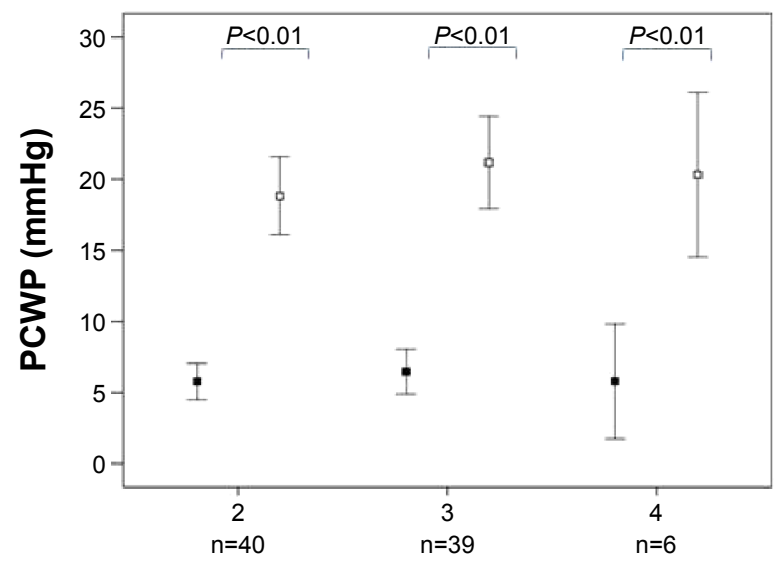

GOLD spirometric grades

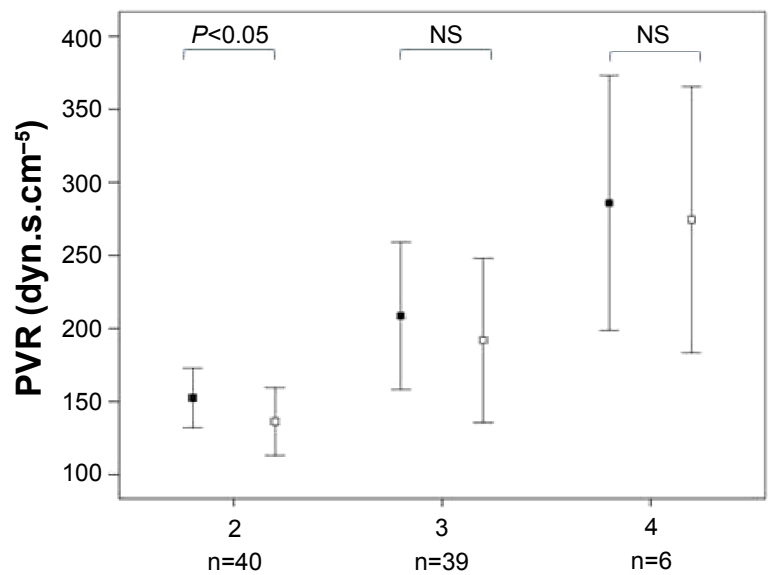

GOLD spirometric grades

Rest $\quad$ Exercise

Figure I Changes from rest to peak exercise in the hemodynamic variables in 85 patients who underwent exercise testing, grouped according GOLD stage. Note: $P$-value differences from rest to exercise (paired $t$-tests).

Abbreviations: $\mathrm{Cl}$, cardiac index; GOLD, Global Initiative for Chronic Obstructive Pulmonary Disease; mPAP, mean pulmonary artery pressure; PCWP, pulmonary capillary wedge pressure; PVR, pulmonary vascular resistance; NS, not significant.

Table 4 Pulmonary hemodynamics during submaximal exercise in patients grouped to the GOLD spirometric grades ( $\mathrm{n}=85$ )

\begin{tabular}{|c|c|c|c|c|c|}
\hline & \multirow[t]{2}{*}{ All } & \multicolumn{3}{|c|}{ GOLD grade } & \multirow{2}{*}{$\begin{array}{l}\text { ANOVA } \\
P \text {-value }\end{array}$} \\
\hline & & 2 & 3 & 4 & \\
\hline Hemodynamics during exercise, $\mathrm{N}$ & 85 & 40 & 39 & 6 & \\
\hline mPAP $(\mathrm{mmHg})$ & $42 \pm 14$ & $38 \pm 11$ & $45 \pm 15$ & $52 \pm 7$ & 0.019 \\
\hline PCWP (mmHg) & $20 \pm 9$ & $19 \pm 9$ & $21 \pm 10$ & $20 \pm 6$ & NS \\
\hline $\mathrm{CO}\left(\mathrm{L} / \mathrm{min} / \mathrm{m}^{2}\right)$ & $11.8 \pm 2.8$ & $12.2 \pm 2.8$ & $11.7 \pm 2.8$ & $9.5 \pm 2.2$ & NS \\
\hline $\mathrm{Cl}\left(\mathrm{L} / \mathrm{min} / \mathrm{m}^{2}\right)$ & $6.5 \pm 1.5$ & $6.7 \pm 1.5$ & $6.3 \pm 1.5$ & $5.4 \pm 1.1$ & NS \\
\hline TPR (dyn's. $\left.\mathrm{cm}^{-5}\right)$ & $315 \pm 174$ & $265 \pm 105$ & $345 \pm 215$ & $454 \pm 146 *$ & 0.014 \\
\hline PVR (dyn $\left.\cdot s \cdot \mathrm{cm}^{-5}\right)$ & $17 \mid \pm 134$ & $136 \pm 72$ & $191 \pm 173$ & $274 \pm 86$ & 0.02 \\
\hline TPG (mmHg) & $22 \pm 11$ & $19 \pm 8$ & $24 \pm 13$ & $3 I \pm 7^{*}$ & 0.02 \\
\hline$\Delta \mathrm{mPAP} / \Delta \mathrm{CO}(\mathrm{mmHg} / \mathrm{L} / \mathrm{min})$ & $4.8 \pm 3.7$ & $4.1 \pm 2.2$ & $5.4 \pm 4.8$ & $6.4 \pm 2.7$ & \\
\hline Abnormal mPAPa, n (\%) & $29(34)$ & $8(20)$ & $17(46)$ & $4(67)$ & \\
\hline$\Delta \mathrm{mPAP} / \Delta \mathrm{CO}>3, \mathrm{n}(\%)$ & $60(7 I)$ & $28(70)$ & $26(67)$ & $6(100)$ & \\
\hline
\end{tabular}

Notes: Data are presented as mean \pm standard deviation. ${ }^{a} \mathrm{mPAP}:<50$ years, $>30 \mathrm{mmHg} ; \geq 50$ years, $>46 \mathrm{mmHg}$. According to Kovacs et al. ${ }^{26}$ Significant differences within each variable are indicated as: *different from GOLD grade 2.

Abbreviations: GOLD, Global Initiative for Chronic Obstructive Pulmonary Disease; $\Delta$, change; ANOVA, analysis of variance; Cl, cardiac index; CO, cardiac output; mPAP, mean pulmonary artery pressure; NS, not significant; PCWP, pulmonary capillary wedge pressure; PVR, pulmonary vascular resistance; TPG, transpulmonary pressure gradient; TPR, total pulmonary resistance. 


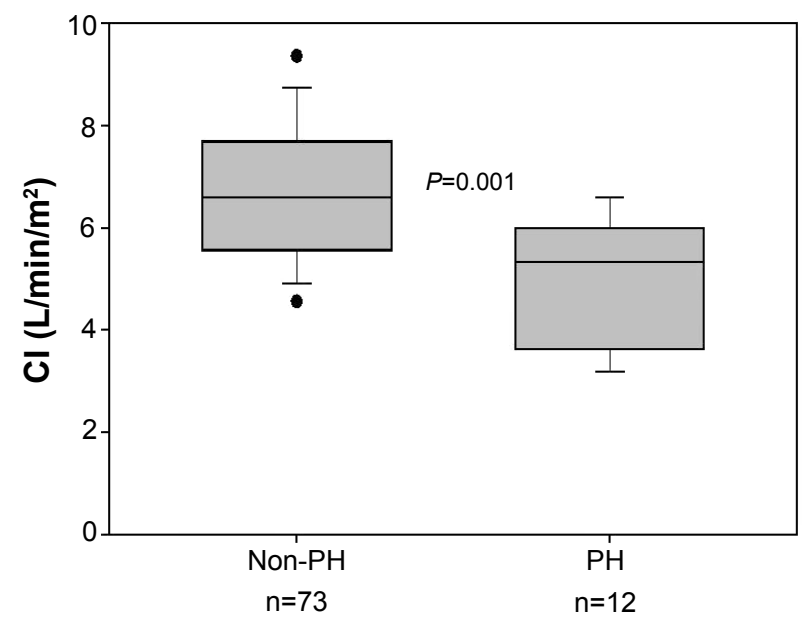

Figure 2 Cardiac index during exercise in patients with and without pulmonary hypertension $(n=85)$.

Note: $\mathrm{P}$-value indicates comparison between $\mathrm{PH}$ and non-PH (Mann-Whitney U-test).

Abbreviations: $\mathrm{Cl}$, cardiac index; $\mathrm{PH}$, pulmonary hypertension.

severity. ${ }^{1,31}$ In the whole cohort, both resting PCWP and RAP were within normal limits. The prevalence of patients with severe PH (2.8\%) in our study is comparable with other reported series. ${ }^{6,79}$ Likewise, patients with severe $\mathrm{PH}$ showed less severe airflow limitation, more severe arterial hypoxemia, and lower DLco than patients with moderate PH. It is important to identify these patients with predominant vascular involvement since they represent a clinically distinct phenotype within the COPD population that carries poor prognosis. ${ }^{6,932}$

The exercise-induced increase in mPAP was interpreted according to the increase in $\mathrm{CO}$ as proposed by recent reports. ${ }^{14,25}$ The latter proposal is based on the concept that during exercise, the pulmonary microcirculation is progressively recruited under physiological conditions, resulting in the maintenance of relatively low arterial pressure despite increasing flow. ${ }^{33}$ The abnormal increase in MPAP during exercise in COPD patients has been documented in different studies. ${ }^{12,14,16,34}$ In spite of the fact that there is no current

Table 5 Arterial blood gas profile at rest and during exercise in 85 patients with or without pulmonary hypertension

\begin{tabular}{llll}
\hline & $\begin{array}{l}\text { No PH } \\
(\mathbf{n}=\mathbf{7 3})\end{array}$ & $\begin{array}{l}\mathbf{P H} \\
(\mathbf{n}=\mathbf{I 2})\end{array}$ & P-value \\
\hline $\mathrm{PaO}_{2}(\mathrm{mmHg})$ & $76 \pm 8$ & $65 \pm 14$ & 0.020 \\
$\mathrm{PaO}_{2}$ exercise $(\mathrm{mmHg})$ & $74 \pm 12$ & $54 \pm 1 \mathrm{I}$ & 0.001 \\
$\mathrm{PaCO}_{2}(\mathrm{mmHg})$ & $38 \pm 4$ & $44 \pm 6$ & 0.006 \\
$\mathrm{PaCO}_{2}$ exercise $(\mathrm{mmHg})$ & $41 \pm 8$ & $47 \pm 6$ & 0.004 \\
\hline
\end{tabular}

Note: $D$ ata are presented as mean \pm standard deviation.

Abbreviations: $\mathrm{PaCO}_{2}$, partial pressure of arterial carbon dioxide; $\mathrm{PaO}_{2}$, partial pressure of arterial oxygen; $\mathrm{PH}$, pulmonary hypertension. definition of exercise-induced $\mathrm{PH}$, we observed that $71 \%$ of the patients developed a "hypertensive response", defined on the basis of pressure/flow relationships. Such an abnormal vascular response was noticed even in moderate grades of COPD severity, whereas it was present in all GOLD 4 patients. The clinical significance of the increased PAP during exercise remains to be established. Conceivably, it could limit exercise capacity. In fact, an increased mPAP has been associated with poor results in the 6 minutes walking test. ${ }^{5,10}$ Furthermore, a PAP threshold $>30 \mathrm{mmHg}$ during exercise is a strong predictor for the development of PH in the long-term. ${ }^{12}$ We also found that PVR does not decrease during exercise in GOLD grades 3 and 4, in contrast with what occurs in healthy subjects. ${ }^{35}$ This fall in PVR during exercise is explained by the distensibility of resistive pulmonary vessels. Reduced pulmonary artery compliance observed in COPD might explain this response. ${ }^{14}$ Furthermore, CI during exercise was lower in patients with associated PH. Although ventilatory impairment is the main factor limiting exercise tolerance in COPD, it cannot be disregarded that hemodynamic alterations may also contribute to exercise intolerance. Indeed, Boerrigter et $\mathrm{al}^{15}$ reported a distinctive exercise pattern in COPD patients with severe PH (mPAP $>40 \mathrm{mmHg}$ ). Although in our study the limited number of patients with severe $\mathrm{PH}$ precluded an analysis in this subset of patients, the finding of lower CI values during exercise in patients with $\mathrm{PH}$ concurs with the findings by Boerrigter et al. ${ }^{15}$

Pulmonary gas exchange impairment was associated with the presence of PH. However, the fact that patients without arterial hypoxemia also had $\mathrm{PH}$ in our cohort underlines the concept that the genesis of $\mathrm{PH}$ is complex and multifactorial. ${ }^{36}$ The weak correlation in COPD between PH and lung function measurements has been largely known and fits with our results. ${ }^{711,34}$ This makes it difficult in daily clinical practice to use predictive models to identify patients with pretest probability of presenting PH. Skjørten et al ${ }^{37}$ suggested that $\mathrm{PaO}_{2}$ values at rest and peak exercise below $71 \mathrm{mmHg}$ and $64 \mathrm{mmHg}$, respectively, indicate the need for further evaluation of coexisting PH. In our study, we failed to find an adequate model with functional variables that could help to predict the presence of $\mathrm{PH}$.

Our investigation has some limitations. First, there is the possibility that selection bias might have influenced the significance of our findings due to its retrospective, singlecenter, and observational design. However, because the purpose of the study was to describe $\mathrm{PH}$ and hemodynamic characteristics in COPD patients with different grades of 
Table 6 Univariate and multivariate logistic regression analysis of variables associated with pulmonary hypertension

\begin{tabular}{|c|c|c|c|c|}
\hline \multirow[t]{2}{*}{ Independent variable } & \multicolumn{2}{|c|}{ Univariate analysis } & \multicolumn{2}{|l|}{ Multivariate analysis* } \\
\hline & OR (Cl 95\%) & $P$-value & OR ( $95 \%$ confidence interval) & $P$-value \\
\hline $\mathrm{PaO}_{2}(\mathrm{mmHg})$ & $0.92(0.89-0.96)$ & $<0.001$ & $0.92(0.88-0.97)$ & 0.001 \\
\hline DLco (mmHg) & $0.86(0.78-0.94)$ & 0.002 & & \\
\hline $\mathrm{PaCO}_{2}(\mathrm{mmHg})$ & $1.07(1.01-1.15)$ & 0.025 & & \\
\hline IC (\% predicted) & $0.97(0.94-0.99)$ & 0.028 & & \\
\hline $\mathrm{FEV}_{1}$ (\% predicted) & $0.96(0.93-0.99)$ & 0.026 & & \\
\hline
\end{tabular}

Note: *From forward stepwise procedure.

Abbreviations: DLco, diffusing capacity for carbon dioxide; FEV , post-bronchodilator forced expiratory volume in I second; IC, inspiratory capacity; OR, odds ratio; $\mathrm{PaCO}_{2}$, partial pressure of arterial carbon dioxide; $\mathrm{PaO}_{2}$, partial pressure of arterial oxygen.

airflow limitation, we believe that the population addresses the needs of the research question. Secondly, since there were no patients with mild airflow limitation (GOLD grade 1) in the study, our findings may not be extensively applicable to this population. Thirdly, the number of women included was small, such that our observations may not be generalized to all individuals with COPD. This sex bias is due to the lower prevalence of COPD in women than in men in our country and the underdiagnoses of COPD in women. ${ }^{38,39}$ Finally, we do not exclude that previous oxygen therapy or vasodilator treatment in these patients could influence the hemodynamic measurements.

\section{Conclusion}

In summary, the present study that analyzed a representative cohort of COPD patients with varying degrees of airflow limitation severity by means of right-heart catheterization shows that $\mathrm{PH}$ at rest is uncommon in patients with moderate airflow limitation but has a similar prevalence to patients with severe and very-severe airflow obstruction from other studies, highlighting that airflow limitation is a poor predictor of PH occurrence. In advanced COPD, the coexistence of pulmonary gas exchange impairment is of great influence on the development of PH. In contrast, an abnormal vascular response to exercise was observed in the majority of patients, even in those with mild airflow limitation, highlighting the notion that pulmonary vascular derangement is an early event in the natural history of COPD. Progression of these abnormalities may lead to the development of PH that restrains the increase of $\mathrm{CO}$ during exercise, which might contribute to limiting exercise tolerance.

\section{Acknowledgments}

The authors would like to thank to Dr Ignasi Garcia-Olivé and Dr Diego Rodriguez for their assistance in the statistical analysis. This paper was supported by grants from the Societat Catalana de Pneumologia, Sociedad Española de Neumología y Cirugía Torácica and Instituto de Salud Carlos III (EC07/90049).

\section{Disclosure}

The authors report no conflicts of interest in this work.

\section{References}

1. Barberà JA, Peinado VI, Santos S. Pulmonary hypertension in chronic obstructive pulmonary disease. Eur Respir J. 2003;21(5): 892-905.

2. Hoeper MM, Barberà JA, Channick RN, et al. Diagnosis, assessment, and treatment of non-pulmonary arterial hypertension pulmonary hypertension. J Am Coll Cardiol. 2009;54(1 Suppl):S85-S96.

3. Seeger W, Adir Y, Barberà JA, et al. Pulmonary hypertension in chronic lung diseases. J Am Coll Cardiol. 2013;62(25 Suppl):D109-D116.

4. Oswald-Mammosser M, Apprill M, BachezP, Ehrhart M, Weitzenblum E. Pulmonary hemodynamics in chronic obstructive pulmonary disease of the emphysematous type. Respiration. 1991;58(5-6):304-310.

5. Sims MW, Margolis DJ, Localio AR, Panettieri RA, Kawut SM, Christie JD. Impact of pulmonary artery pressure on exercise function in severe COPD. Chest. 2009;136(2):412-419.

6. Thabut G, Dauriat G, Stern JB, et al. Pulmonary hemodynamics in advanced COPD candidates for lung volume reduction surgery or lung transplantation. Chest. 2005;127(5):1531-1536.

7. Scharf SM, Iqbal M, Keller C, et al. Hemodynamic characterization of patients with severe emphysema. Am J Respir Crit Care Med. 2002; 166(3):314-322.

8. Doi M, Nakano K, Hiramoto T, Kohno N. Significance of pulmonary artery pressure in emphysema patients with mild-to-moderate hypoxemia. Respir Med. 2003;97(8):915-920.

9. Chaouat A, Bugnet AS, Kadaoui N, et al. Severe pulmonary hypertension and chronic obstructive pulmonary disease. Am J Respir Crit Care Med. 2005;172(2):189-194.

10. Cuttica MJ, Kalhan R, Shlobin OA, et al. Categorization and impact of pulmonary hypertension in patients with advanced COPD. Respir Med. 2010;104(12):1877-1882.

11. Andersen KH, Iversen M, Kjaergaard J, et al. Prevalence, predictors, and survival in pulmonary hypertension related to end-stage chronic obstructive pulmonary disease. J Heart Lung Transplant. 2012; 31(4): 373-380.

12. Kessler R, Faller M, Weitzenblum E, et al. "Natural history" of pulmonary hypertension in a series of 131 patients with chronic obstructive lung disease. Am J Respir Crit Care Med. 2001;164(2):219-224.

13. Rabe KF, Hurd S, Anzueto A, et al. Global strategy for the diagnosis, management, and prevention of chronic obstructive pulmonary disease: GOLD executive summary. Am J Respir Crit Care Med. 2007; 176(6):532-555.

14. Hilde JM, Skjørten I, Hansteen V, et al. Haemodynamic responses to exercise in patients with COPD. Eur Respir J. 2013;41(5):1031-1041. 
15. Boerrigter BG, Bogaard HJ, Trip P, et al. Ventilatory and cardiocirculatory exercise profiles in COPD: the role of pulmonary hypertension. Chest. 2012;142(5):1166-1174.

16. Pynnaert C, Lamotte M, Naeije R. Aerobic exercise capacity in COPD patients with and without pulmonary hypertension. Respir Med. 2010; 104(1):121-126.

17. Barberà JA, Roger N, Roca J, Rovira I, Higenbottam TW, RodriguezRoisin R. Worsening of pulmonary gas exchange with nitric oxide inhalation in chronic obstructive pulmonary disease. Lancet. 1996; 347(8999):436-440.

18. Roger N, Barberà JA, Roca J, Rovira I, Gómez FP, Rodriguez-Roisin R. Nitric oxide inhalation during exercise in chronic obstructive pulmonary disease. Am J Respir Crit Care Med. 1997;156(3 Pt 1):800-806.

19. Agustí AG, Barberá JA, Roca J, Wagner PD, Guitart R, RodriguezRoisín R. Hypoxic pulmonary vasoconstriction and gas exchange during exercise in chronic obstructive pulmonary disease. Chest. 1990;97(2): $268-275$.

20. Ribas J, Díaz O, Barberà JA, et al. Invasive exercise testing in the evaluation of patients at high-risk for lung resection. Eur Respir J. 1998; 12(6):1429-1435.

21. Ribas J, Jiménez MJ, Barberà JA, et al. Gas exchange and pulmonary hemodynamics during lung resection in patients at increased risk: relationship with preoperative exercise testing. Chest. 2001;120(3): 852-859.

22. Peinado VI, Gómez FP, Barberà JA, et al. Pulmonary vascular abnormalities in chronic obstructive pulmonary disease undergoing lung transplant. J Heart Lung Transplant. 2013;32(12):1262-1269.

23. Blanco I, Gimeno E, Munoz PA, et al. Hemodynamic and gas exchange effects of sildenafil in patients with chronic obstructive pulmonary disease and pulmonary hypertension. Am J Respir Crit Care Med. 2010; 181(3):270-278.

24. Vestbo J, Hurd SS, Agustí AG, et al. Global strategy for the diagnosis, management, and prevention of chronic obstructive pulmonary disease: GOLD executive summary. Am J Respir Crit Care Med. 2013; 187(4):347-365.

25. Saggar R, Lewis GD, Systrom DM, Champion HC, Naeije R, Saggar R. Pulmonary vascular response to exercise: a haemodynamic observation. Eur Respir J. 2012;39(2):231-234.

26. Kovacs G, Berghold A, Scheidl S, Olschewski H. Pulmonary arterial pressure during rest and exercise in healthy subjects: a systematic review. Eur Respir J. 2009;34(4):888-894.
27. Miller MR, Crapo R, Hankinson J, et al. General considerations for lung function testing. Eur Respir J. 2005;26(1):153-161.

28. Roca J, Sanchis J, Agusti-Vidal A, et al. Spirometric reference values for a Mediterranean population. Bull Eur Physiopathol Respir. 1986;22(3):217-224.

29. Roca J, Rodriguez-Roisin R, Cobo E, Burgos F, Perez J, Clausen JL. Single-breath carbon monoxide diffusing capacity prediction equations from a Mediterranean population. Am Rev Respir Dis. 1990;141(4 Pt 1): 1026-1032.

30. Nelson LD, Rutherford EJ. Principles of hemodynamic monitoring. In: Pinsky MR, Dhainaut JF, editors. Pathophysiologic Foundations of Critical Care. Baltimore, MD: Williams and Wilkins; 1993:3-22.

31. Barberà JA. The pulmonary vasculature of COPD. In: Rennard SI, Rodríguez-Roisin R, Huchon G, Roche N, editors. Clinical management of chronic obstructive lung disease. 2nd ed. New York: Informa Healthcare; 2008:189-205.

32. Hurdman J, Condliffe R, Elliot CA, et al. Pulmonary hypertension in COPD: results from the ASPIRE registry. Eur Respir J. 2013;41(6): 1292-1301.

33. Lau EM, Manes A, Celermajer DS, Galiè N. Early detection of pulmonary vascular disease in pulmonary arterial hypertension: time to move forward. Eur Heart J. 2011;32(20):2489-2898.

34. Christensen CC, Ryg MS, Edvardsen A, Skjønsberg OH. Relationship between exercise desaturation and pulmonary haemodynamics in COPD patients. Eur Respir J. 2004;24(4):580-586.

35. Kovacs G, Olschewski A, Berghold A, Olschewski H. Pulmonary vascular resistances during exercise in normal subjects: a systematic review. Eur Respir J. 2012;39(2):319-328.

36. Peinado VI, Pizarro S, Barberà JA. Pulmonary vascular involvement in COPD. Chest. 2008;134(4):808-814.

37. Skjørten I, Hilde JM, Melsom MN, Hansteen V, Steine K, Humerfelt S. Pulmonary artery pressure and $\mathrm{PaO}_{2}$ in chronic obstructive pulmonary disease. Respir Med. 2013;107(8):1271-1279.

38. Miravitlles M, Soriano JB, Garcia-Rio R, et al. Prevalence of COPD in Spain: impact of undiagnosed COPD on quality of life and daily life activities. Thorax. 2009;64(10):863-868.

39. Ancochea J, Miravitlles M, García-Río F, et al. Underdiagnoses of chronic obstructive pulmonary disease in women: quantification of the problem, determinants and proposals for action. Arch Bronconeumol. 2013;49(6):223-229. English, Spanish.
International Journal of COPD

\section{Publish your work in this journal}

The International Journal of COPD is an international, peer-reviewed journal of therapeutics and pharmacology focusing on concise rapid reporting of clinical studies and reviews in COPD. Special focus is given to the pathophysiological processes underlying the disease, intervention programs, patient focused education, and self management protocols.

\section{Dovepress}

This journal is indexed on PubMed Central, MedLine and CAS. The manuscript management system is completely online and includes a very quick and fair peer-review system, which is all easy to use. Visit http://www.dovepress.com/testimonials.php to read real quotes from published authors. 